\title{
A novel compact dual band RFID handheld reader antenna for microwave ISM band application
}

\author{
Wahiba Belgacem, Miloud Bousahla, Sidi Mohammed Meriah \\ Laboratory of Telecommunications of Tlemcen (LTT), Department of Telecommunications Faculty of Technology, \\ University of Tlemcen, Algeria
}

\begin{tabular}{|c|c|}
\hline Article Info & ABSTRACT \\
\hline & \multirow{6}{*}{$\begin{array}{l}\text { This paper presents a new design of dual band RFID reader antenna for ISM- } \\
\text { band industrial science and medical applications at } 2.4 \mathrm{GHz} \text { and } 5.8 \mathrm{GHz} \text {. The } \\
\text { antenna is designed and physically built using FR } 4 \text { substrate and taking a } 1.5 \\
\text { thickness, } 4.3 \text { relative permittivity and } 0.025 \text { loss tangents. Different slots have } \\
\text { been introduced to reduce the antenna dimensions and to achieve the dual band } \\
\text { for microwave ISM band application. The dimension of the proposed antenna is } \\
34 \times 34 \times 1.5 \mathrm{~mm} 3 \text {, which it could be easily integrated into RFID readers. } \\
\text { Numerical simulations have been performed using computer simulation } \\
\text { technology (CST) Microwave Studio software. A parametric study was } \\
\text { investigated in order to show the effect of slots variation and to obtain the desired } \\
\text { functional characteristics. Experimental results show a good agreement with } \\
\text { results obtained by simulations. A satisfactorily omnidirectional for the radiation } \\
\text { patterns across the antenna operation bands was obtained. }\end{array}$} \\
\hline Received Oct 17, 2020 & \\
\hline Revised Mar 28, 2021 & \\
\hline Accepted Jun 18, 2021 & \\
\hline Keywords: & \\
\hline $\begin{array}{l}\text { Computer simulation } \\
\text { technology } \\
\text { RFID }\end{array}$ & \\
\hline
\end{tabular}

This is an open access article under the CC BY-SA license.

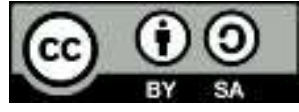

\section{Corresponding Author:}

Wahiba Belgacem

Laboratory of Telecommunications of Tlemcen (LTT)

Department of Telecommunications

Faculty of Technology, University of Tlemcen, Algeria

BP 230 - 13000 Chetouane Tlemcen, Algéria

Email: belgacem_wahiba@yahoo.fr

\section{INTRODUCTION}

Radio frequency identification (RFID) is a technology automatically encodes or stores digital data into an RFID tags (also known as RFID transponders). RFID transponder is affixed to an object, and which permits to a radio wave device reading or tracking data regarding the object remotely. In contrast to bar-code technology, which requires that codes printed on a label pass in direct view in front of an optical reader to allow the corresponding data to be read, RFID tags can be read without a direct line of sight [1]-[25]. This ease and speed of reading make RFID technology, particularly suitable for a large number of applications where the individual reading of each bar code would slow down the information acquisition process. The RFID system consists of an RFID tag that contains an integrated circuit connected to an antenna and encapsulated in a protective bracket, which depends on the needs of the intended application and an RFID reader is a receiver, transmitter controlled by a microprocessor or a digital signal processor. Using an antenna to which it is connected, the reader "captures" the data stored in the tags and then transmits it to a computer for processing [1].

Many operating frequencies have been assigned to the RFID systems, there are the low-frequency (LF) around $125 \mathrm{KHz}$, the high-frequency (HF) around $13.56 \mathrm{MHz}$, the ultra-high-frequency (UHF) from $860 \mathrm{MHz}$ to $960 \mathrm{MHz}$ and the microwave band (MW) around $2.45 \mathrm{GHz}$ or $5.8 \mathrm{GHz}$. The important components in the RFID system are the reader and tag antenna, and their capability determines the 
performance of the whole system. RFID technologies require antennas with small sizes and high performances such as a large bandwidth, a multi-band operation [3]-[10] and, a high gain [11], [12]. There exists various techniques to realize multi-band antenna, for example, metamaterial technology [6], [14], [15], multilayer substrates [14], fractal technology [6], [16], slot reactive loading [4], and [17]-[20]. A slot loading can not only realize antenna multi band, but also realize broadband and miniaturization. A number of antennas have been proposed previously [4], [13], [16]-[33]. However, many of them they are not compact and sometimes a physical realisation of the antenna is difficult in reality.

In this paper, we propose a new design of a compact and low profile dual band RFID reader antenna for ISM band application. Our antenna is with one connection port dualband reader antenna. Two connection ports dual-band reader antenna puts additional requirement on sufficient port isolation [25]. The design initially begins with a conventional rectangular microstrip patch antenna. Then an intermediate design is given with introducing five $\mathrm{C}$-shape slots to achieve the dual band and to improve radiation characteristics such as return loss and gain. Finally, a new last design is proposed by introducing another rectangular slot in the center to the radiating element to achieve each resonant frequency $(2.4 \mathrm{GHz}$ and $5.8 \mathrm{GHz})$ and to obtain a good adaptation and gain in both frequencies. A good characteristic were achieved by using slots technique. All antenna structures are designed and analysed using computer simulation technology (CST) Microwave Studio software. A detailed design process and a parametric study was performed and discussed. A simulation and experimental studies are given for our final new antenna. The antenna was physically built using FR4 substrate in telecommunications laboratory, Tlemcen. We provide a comparison between experiments and simulations results of the antenna return loss. The antenna has a good agreement between measurements and simulations. Finally, we validate our results and we notice that our new antenna design has a comparable dimension and offers a better adaptation and gain values compared with some other recent published antennas in literatures.

\section{PREPOSED ANTENNA}

The structure of the proposed RFID reader antenna is given in Figure 1. This antenna is simulated on computer simulation technology (CST) software. Designed on a low cost FR4 substrate that has a permittivity of 4.3 , loss tangent of 0.025 and a compact size of $(34 \times 34 \times 1.5) \mathrm{mm}^{3}$. The radiating patch is connected to a rectangular feed-line with a width of $\mathrm{W}_{3}=3.89 \mathrm{~mm}$ and a length of $\mathrm{h}_{3}=10 \mathrm{~mm}$. On the other side of the substrate, a conducting partial ground plane, with a width of $\mathrm{W}=34 \mathrm{~mm}$ and a length of $\mathrm{h}_{1}=9$ $\mathrm{mm}$, is placed. The patch and the ground plane are both made of copper material with thickness $\mathrm{t}=0.035$ $\mathrm{mm}$. The antenna is connected to a $50 \Omega$ SMA connector for signal transmission. The width of the microstrip feed-line is adjusted to improve matched impedance. Table 1 shows optimized dimensions of the patch, slots, ground plane and substrate. Slots were embedded in the printed patch to achieve the proposed antenna design and the desired resonant frequency, and to also improve the return loss. Several optimization processes were applied by using computer simulation technology (CST) software. We properly select the dimensions, positions and number of slots.
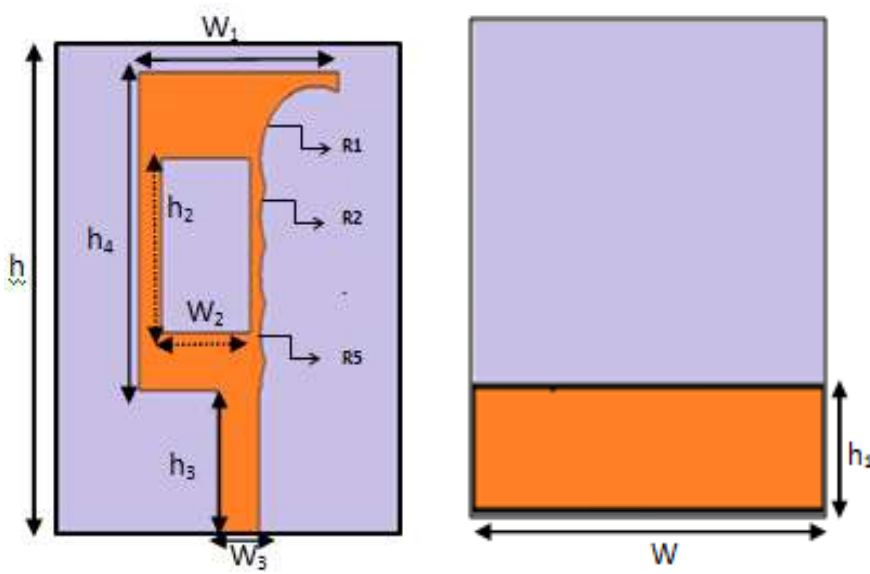

Table 1.Optimized dimensions of the proposed RFID dual band reader antenna

\begin{tabular}{cc}
\hline Parameters & $\begin{array}{c}\text { Proposed Antenna (ANT3) } \\
\text { Dimensions [mm] }\end{array}$ \\
\hline $\mathrm{H}$ & 34 \\
$\mathrm{~h}_{1}$ & 9 \\
$\mathrm{~h}_{2}$ & 12 \\
$\mathrm{~h}_{3}$ & 10 \\
$\mathrm{~h}_{4}$ & 18 \\
$\mathrm{~W}$ & 34 \\
$\mathrm{~W}_{1}$ & 22 \\
$\mathrm{~W}_{2}$ & 8 \\
$\mathrm{~W}_{3}$ & 3.89 \\
$\mathrm{R}_{1}=\mathrm{R}_{2}=\ldots=\mathrm{R}_{5}$ & 5 \\
\hline
\end{tabular}

Figure 1. The geometry of the proposed RFID dual band reader antenna 


\section{DESIGN PROCEDURE}

In Figure 2, we propose first a design antenna (ANT1). A conventional rectangular microstrip patch antenna, which is designed by applying equations of the transmission line model to resonate around $2.4 \mathrm{GHz}$ ISM band, see [11]. A rectangular radiating patch is placed on the top side of the FR4 substrate and it is fed with a microstrip line. On backside of the substrate, a partial ground plane is embedded. The size of this antenna (ANT1), its performance and its characteristics should meet the RFID system requirements. Then, in order to achieve the dual band, another antenna structure (ANT2) is proposed in Figure 2 by adding five $\mathrm{C}$-shape slots. However this antenna was not adapted to the desired resonant frequencies. Therefore, to also achieve this, a new desired antenna (ANT3) is finally obtained, see Figure 2. Several optimization processes were applied to fillfull or satisfay each resonant frequency. Another rectangular slot was introduced in the center to the radiating element. Then, a geometrical modification of the slot dimensions was applied to boost the antenna characteristics. In particular to obtain a good adaptation and gain in both frequencies. These antennas are printed on the front side of FR4 substrate with the same partial ground plane. The proposed antenna ANT3 gives dual-band characteristic covering $2.4 \mathrm{GHz}$ and $5.8 \mathrm{GHz}$.

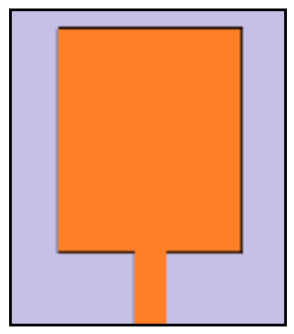

ANT 1

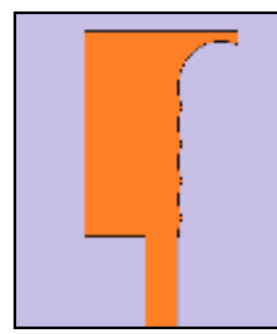

ANT 2

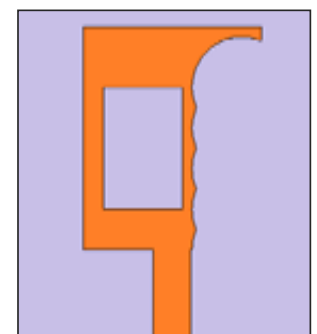

ANT 3

Figure 2. Antenna design and simulation evolution process

A comparison of the evolution the return losses of the three proposed structures designs as a function of frequency is given in Figure 3. We notice that the first antenna (ANT1) was adapted near the desired frequencies. The second design (ANT2) with five slots has a poor return loss factor and there exists a frequency deviation from the desired frequencies, i.e $2.4 \mathrm{GHz}$ and $5.8 \mathrm{GHz}$. Finally, for the last antenna design (ANT3), we notice that the return loss and the impedance matching was improved by adding the rectangular slot and with adjusting its dimension and position along the radiating element. The antenna was adapted at the exact frequencies.

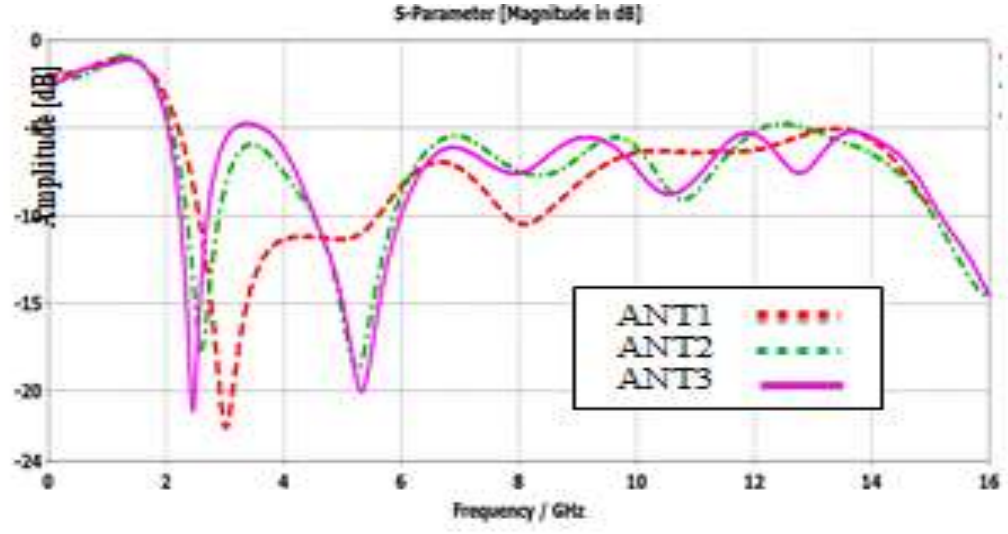

Figure 3. Simulated return losses versus frequency for the three designed antennas

\subsection{Parametric study}

A parametric study of the proposed antenna was performed using CST Microwave Studio. In fact, we variate the slot (rectangular) width, length, and the position to see their effects on the impedance matching and to optimize the final design. However, the only one that has a significant effect on the results 
obtained is the slot width. The Figure 4, shows a comparison graph of the evolution of the return losses when the slot width is increased from $2.5 \mathrm{~mm}$ to $8 \mathrm{~mm}$. Where, the return loss peaks were increased by increasing the slot width. Table 2 presents a comparaison of the obtained results in terms of impedance matching, gain and the voltage standing wave ratio (VSWR).

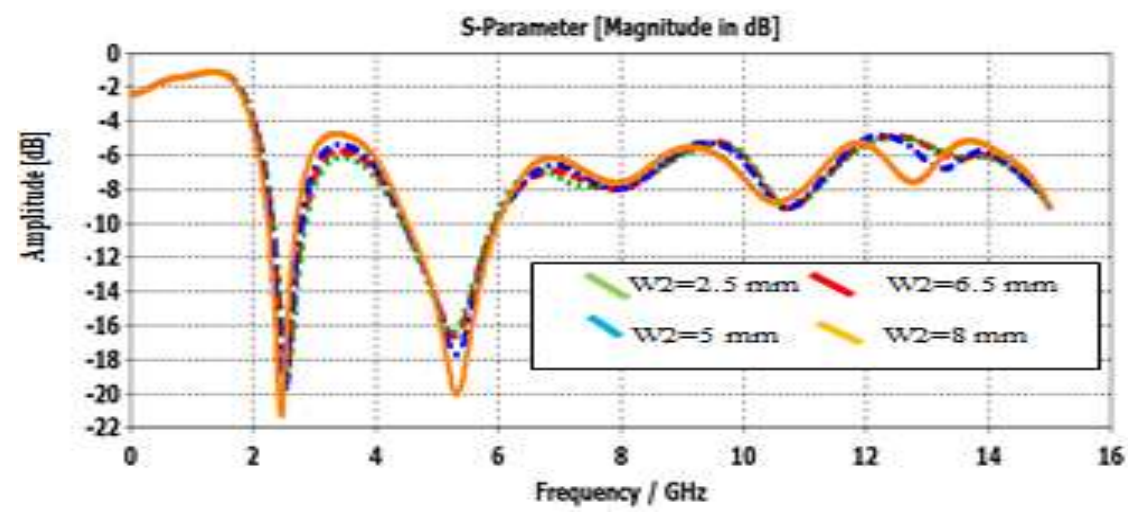

Figure 4. Return losses for different width values W2 of slot

Table 2. The simulation results antenna for different values of slot width

\begin{tabular}{ccccccc}
\hline & \multicolumn{2}{c}{ Return loss [dB] } & \multicolumn{2}{c}{ Gain[dBi] } & \multicolumn{2}{c}{ VSWR } \\
Width $[\mathrm{mm}]$ & $\mathrm{f}=2.4 \mathrm{GHz}$. & $\mathrm{f}=5.8 \mathrm{GHz}$. & $\mathrm{f}=2.4 \mathrm{GHz}$. & $\mathrm{f}=5.8 \mathrm{GHz}$. & $\mathrm{f}=2.4 \mathrm{GHz}$. & $\mathrm{f}=5.8 \mathrm{GHz}$. \\
\hline $\mathrm{W}_{2}=2.5$ & -12.77 & -11.04 & 1.63 & 4.61 & 1.61 & 1.79 \\
$\mathrm{~W}_{2}=5$ & -13.26 & -11.23 & 1.64 & 4.76 & 1.59 & 1.77 \\
$\mathrm{~W}_{2}=6.5$ & -14.74 & -11.66 & 1.669 & 4.962 & 1.44 & 1.7 \\
$\mathrm{~W}_{2}=8$ & -18.53 & -12.07 & 1.724 & 5.02 & 1.26 & 1.66 \\
\hline
\end{tabular}

\section{SIMULATIONS AND RESULTS}

In the following, we present some other simulations of the proposed antenna to investigate the biband operation properties, for example, to show results of radiation patterns, the gain, the efficiency, and the current distribution.

\subsection{Return loss versus frequency}

The Figure 5 shows the simulation result of the return loss versus frequency of the proposed antenna. The graph shows clearly that the design provides a good return loss of $-18.95 \mathrm{~dB}$ and $-12.09 \mathrm{~dB}$ at the operating frequencies $2.4 \mathrm{GHz}$ and $5.8 \mathrm{GHz}$ respectivily. The Figure 6 shows the simulation result of the voltage standing wave ratio (VSWR) as a function of frequency. The simulation demonstrates that the antenna is well adapted and provides a better VSWR of 1.26 at $2.4 \mathrm{GHz}$ and 1.66 at $5.8 \mathrm{GHz}$.

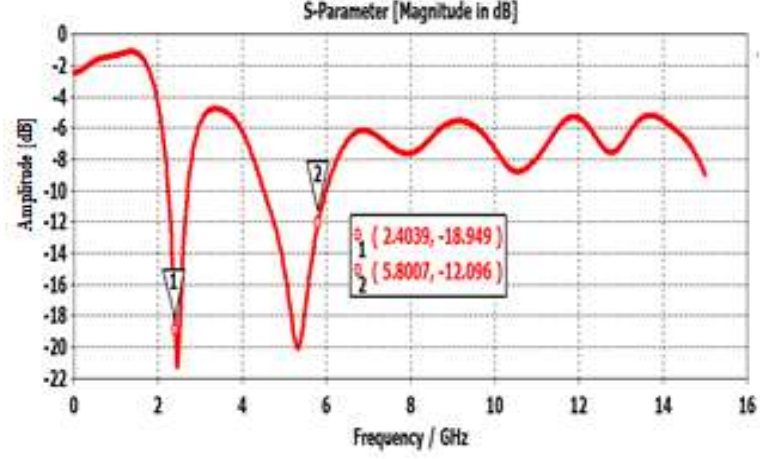

Figure 5. Simulated return loss versus frequency of the proposed antenna

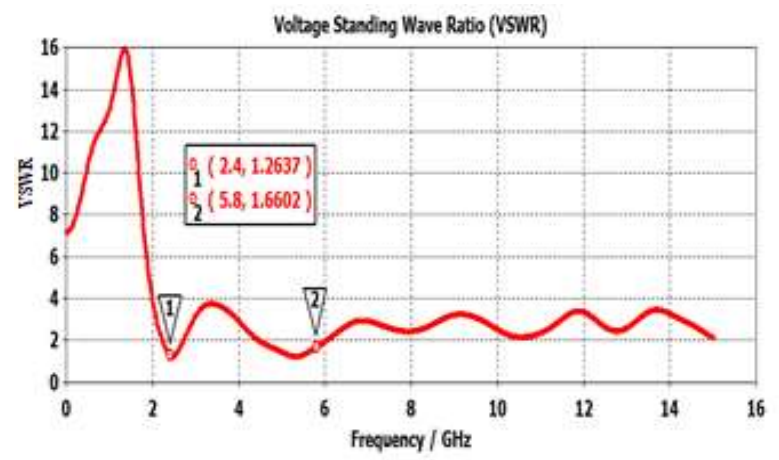

Figure 6. VSWR of the proposed antenna 


\subsection{Radiation patterns and gain}

Figures 7 presents a 3D radiation pattern at the resonant frequencies 2.4 and $5.8 \mathrm{GHz}$ of the antenna. For the two frequencies, we notice that the radiated power is concentrated along the $\mathrm{x}-\mathrm{z}$ plane. The Figure 8 shows the gain at the operating frequency bands for the proposed antenna. The gain obtained of this antenna is equal to $1.7 \mathrm{dBi}$ at $2.4 \mathrm{GHz}$ and $5 \mathrm{dBi}$ at $5.8 \mathrm{GHz}$. Where, these gains satisfy the requirement of RFID applications in far field. Figures 9 present the 2D radiation pattern in the E-plane and H-plane at the resonant frequencies 2.4 and $5.8 \mathrm{GHz}$ of the antenna. We notice that in the E-plane and $\mathrm{H}$-plane the antenna radiates bidirectionally at $2.4 \mathrm{GHz}$ and provides an omnidirectional radiation pattern at $5.8 \mathrm{GHz}$.

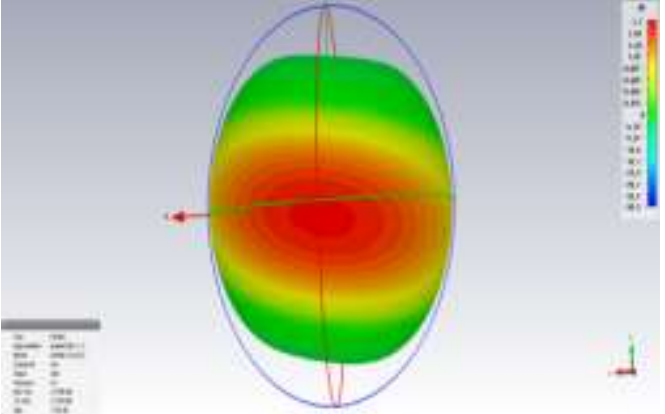

(a)

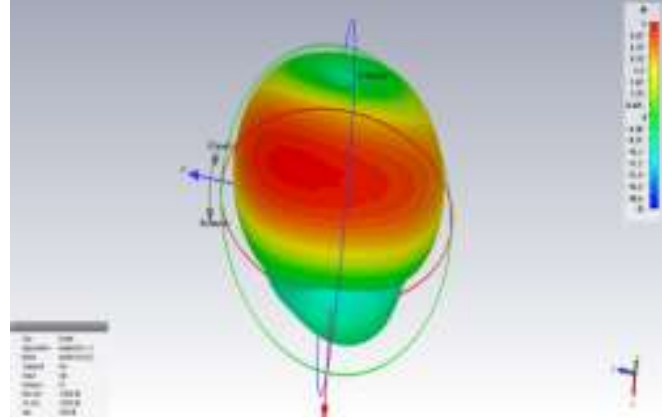

(b)

Figure 7. Simulated 3D radiation patterns at (a) $2.4 \mathrm{GHz}$ and (b) $5.8 \mathrm{GHz}$

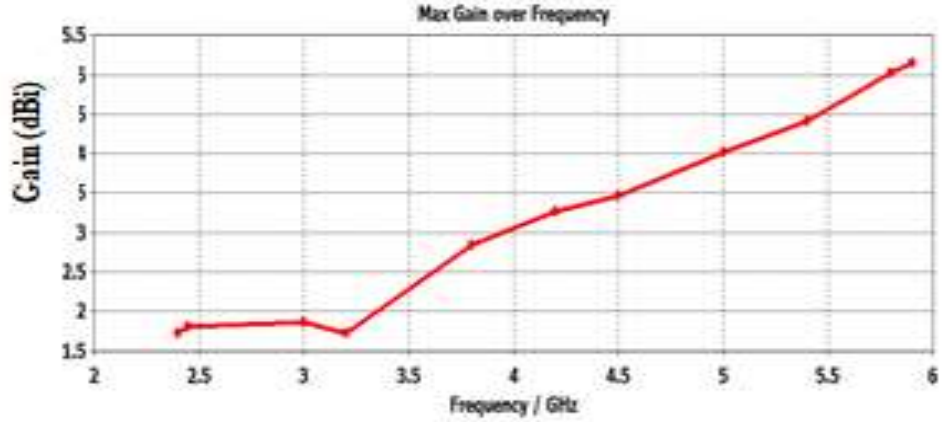

Figure 8. Simulated gain of the proposed antenna versus frequency

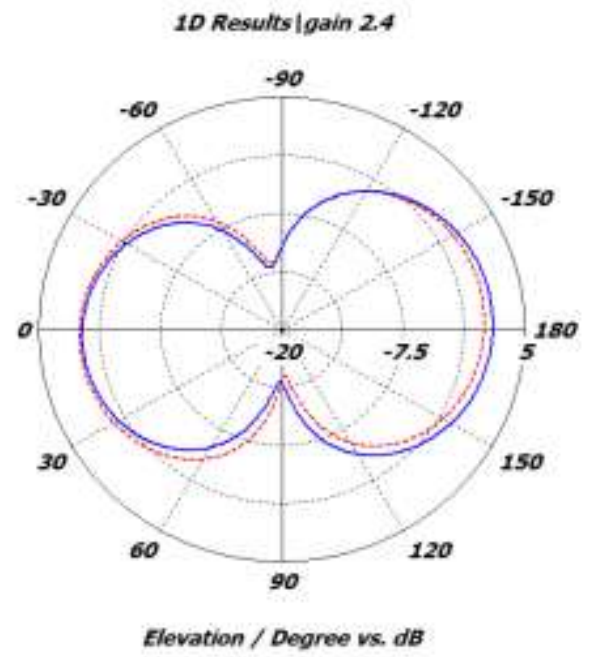

(a)

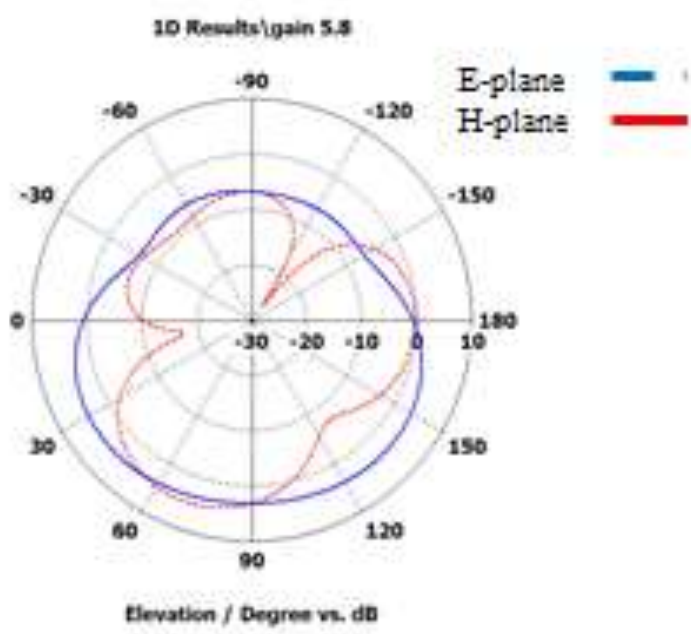

(b)

Figure 9. Simulated 2D radiation pattern at $2.4 \mathrm{GHz}$ (a) and $5.8 \mathrm{GHz}$ (b) 


\subsection{Surface current distributions}

Figures 10 shows the simulation results of surface current distributions of the antenna at frequencies 2.4 and $5.8 \mathrm{GHz}$. We notice that the current is concentrated on the microstrip line and around the slot. Also, strong distributions at $2.4 \mathrm{GHz}$, those are concentrated near the right-edge of the patch. Where, the radiation characteristics are stable. We notice that performances are strongly affected by the number and radius of slots and by the micro-strip feed-line dimensions.

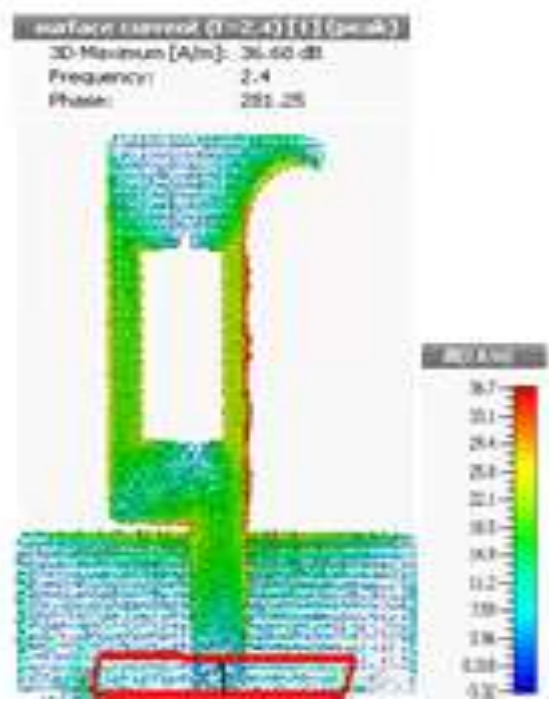

(a)

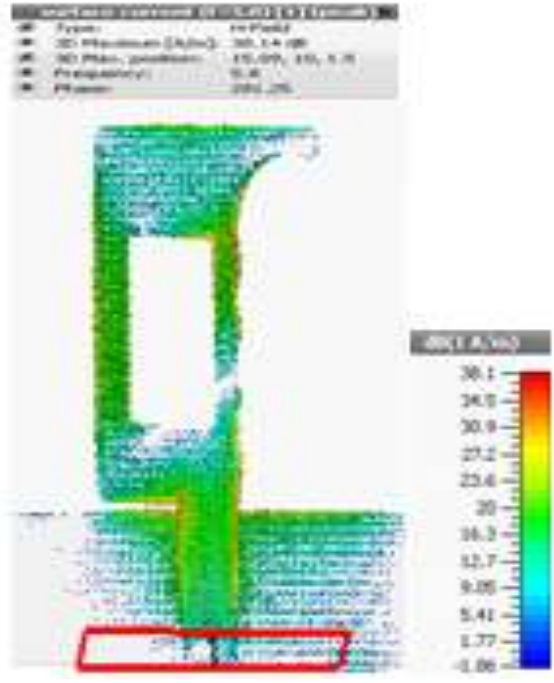

(b)

Figure 10. Surface current distribution of the proposed antenna at $2.4 \mathrm{GHz}$ and $5.8 \mathrm{GHz}$

\section{A PHYSICAL REALISATION OF THE CIRCUIT ANTENNA}

In Figure 11, some photographs were taken of the physical prototype of the dual band RFID Reader antenna using FR4 substrate (thickness of $1.5 \mathrm{~mm}$, a relative permittivity of 4.3 and loss tangent of 0.025 ). The Figure 11(a) presents the front view and Figure 11(b) shows the back view. The achievement of the prototype of the antenna permits to check its performances and to validate our results obtained by simulations.

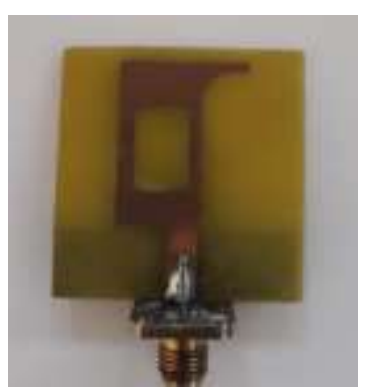

(a)

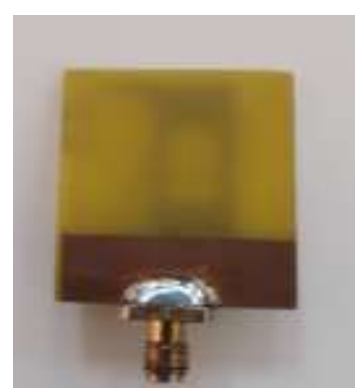

(b)

Figure 11. Photographs of the fabricated antenna, (a) Front view, (b) Back view

\section{MEASUREMENT RESULTS}

We used a network analyser for the experiment or the measurement procedure to observe the reflection characteristics, as shown in Figure 12. The measured and simulated return loss curves of the proposed antenna are given in Figure 13. We notice that the measured return loss is in agreement with the simulated one across the whole operating band with an acceptable discrepancy for the resonance frequency $2.4 \mathrm{GHz}$ due to the manufacturing tolerance and the effect of the feeding cable. 


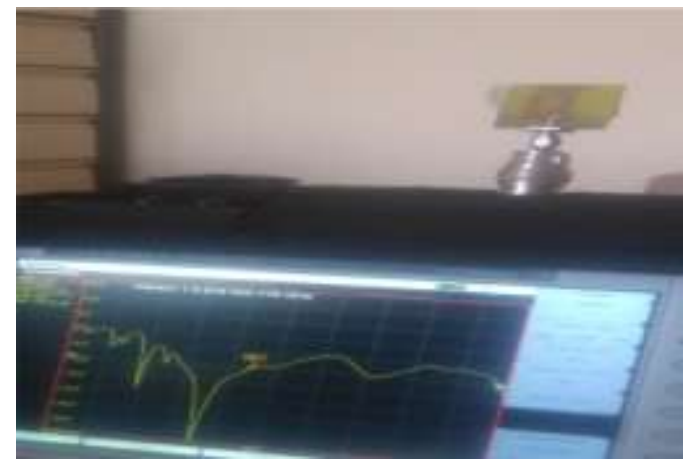

Figure 12. Measured return loss using a network analyzer

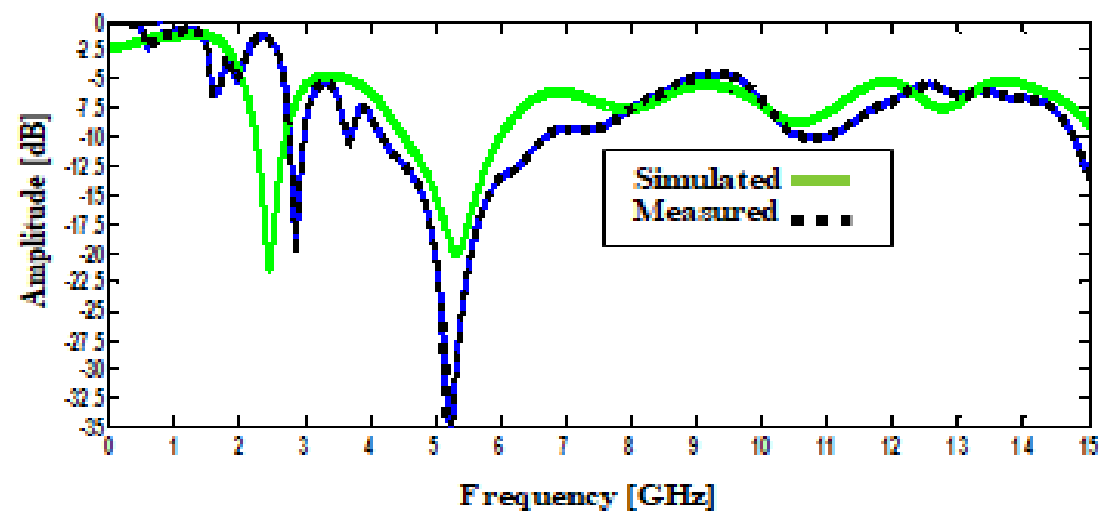

Figure 13. Measured and simulated return loss of the proposed antenna

\section{PERFORMANCE COMPARISON WITH PREVIOUS PUBLISHED LITERATURE}

Table 3 summarized a comparison of our antenna above and some other recent published antennas in terms of size, adaptation and gain. It is clearly shown that our antenna has a comparable dimension and offers a better adaptation and gain values compared with other antennas given in [2], [4], [5].

Table 3. Performance comparison of our antenna with some other recent antennas that we found in literature

\begin{tabular}{lccc}
\hline \multicolumn{1}{c}{ Ref. } & Band-wide $(\mathrm{S} 11<-10 \mathrm{~dB})$ & Size $(\mathrm{mm})$ & Gain $(\mathrm{dBi})$ \\
\hline [2] Monopole Antenna & $2.35-2.74 \mathrm{GHz}, 5.2-6.5 \mathrm{GHz}$ & $38 \mathrm{~mm} \times 35 \mathrm{~mm} 1.5 \mathrm{~mm}$ & $1.36(\mathrm{dBi}), 2.3(\mathrm{dBi})$ \\
[4] patch antenna & $2,39-2,496 \mathrm{GHz}, 5.585-6,164 \mathrm{GHz}$ & $26 \mathrm{~mm} \times 28 \mathrm{~mm} \times 1,6 \mathrm{~mm}$ & $2,09(\mathrm{dBi}), 3,51(\mathrm{dBi})$ \\
[5] metamaterial & $2.372-2.521 \mathrm{GHz}, 5.7136-5.921 \mathrm{GHz}$ & $34 \mathrm{~mm} \times 34 \mathrm{~mm} \times 1,6 \mathrm{~mm}$ & $1,925(\mathrm{dBi}), 3,385(\mathrm{dBi})$ \\
microstrip antenna & & & \\
Proposed antenna & $2,26-2,68 \mathrm{GHz}, 4.536-5.985 \mathrm{GHz}$ & $34 \mathrm{~mm} \times 34 \mathrm{~mm} \times 1,5 \mathrm{~mm}$ & $1.7(\mathrm{dBi}), 5(\mathrm{dBi})$ \\
\hline
\end{tabular}

\section{CONCLUSION}

A new design of a compact and low profile dual band RFID reader antenna for ISM band applications has been proposed, implemented and measured. Good characteristics were achieved by using the slots technique. Numerous slots have been introduced along the length of the radiating element to reduce the antenna dimensions, to achieve the dual band and to improve radiation characteristics such as return loss and gain. A good agreement between measurement and the result of simulations, which validate this antenna. Our antenna is covering a dual band with good characteristics.

\section{FUNDING}

This research was supported by the Directorate-General of scientific research and technological development (Project no. 22/Univ.Tlemcen/DGRSDT: "Antennas design and optimization for RFID systems". 


\section{ACKNOWLEDGMENTS}

The authors would like to gratefully acknowledge Pr. FEHAM Mohamed, from STIC laboratory of the University of Tlemcen, for his technical support in providing the experimental data.

\section{REFERENCES}

[1] K Finkenzeller, "RFID Handbook: Fundamentals and Applications in Contactless Smart Cards and Identification," 3rd Edition. John Wiley and Sons Inc. New York. 2010, doi: 10.1002/0470868023.ch9.

[2] A. El Hamraoui, E. Abdelmounim, J. Zbitou, H. Bennis, M. Latrach, "A New Design of a CPW-Fed Dual-Band Monopole Antenna for RFID Readers," International Journal of Electrical and Computer Engineering, vol. 8, no. 2, pp. 1040-1047, 2018, doi: 10.11591/ijece.v8i2.pp1040-1047.

[3] Ankita Batta Ruchi, "Multiband Microstrip Patch Antenna for RFID Applications," International Journal of Advanced Research in Computer and Communication Engineering, vol. 5, no. 8, 2016.

[4] Y. Hachimi, Yassine Gmih, E. Makroum, A. Farchi, "A compact dual-band antenna including symmetrical slots for 2.45/5.8 GHz handheld RFID reader applications," 2018 4th International Conference on Optimization and Applications (ICOA), 2018, doi: 10.1109/ICOA.2018.8370532.

[5] A. Ennajih, B. Nasiri, J. Zbitou, A. Errkik, M. Latrach, "A New Design of a Compact Metamaterial Antenna for RFID Handheld Applications," Majlesi Journal of Electrical Engineering, vol. 13, no. 2, pp. 41-47, 2019.

[6] J. Anguera, E. Martinez, C. Puente, C. Borja, J. Soler, "Broad-band dual-frequency microstrip patch antenna with modified Sierpinski fractal geometry," in Antennas and Propagation, IEEE Transactions on, vol. 52, no. 1, pp. 66-73, 2004, doi: 10.1109/TAP.2003.822433.

[7] N. M. Sahar, M. T Islam, N. Misran, "Design of dualband antenna for RFID applications," International Journal of Electrical and Computer Engineering (IJECE), vol. 9, no. 4, pp. 3146-3152, 2019, doi: 10.11591/ijece.v9i4.pp3146-3152.

[8] F. Lai, Ji. Yang, Y. Chen, "Compact Dual-Band Circularly Polarized Antenna Using Double Cross Dipoles for RFID Handheld Readers," IEEE Antennas and Wireless Propagation Letters, vol. 19, no. 8, pp. 1429-1433, 2020, doi: 10.1109/LAWP.2020.3004881.

[9] A. Pandey, R. Mishra "Compact Dual Band Monopole Antenna for RFID and WLAN Applications," Science direct, vol. 5, no. 1, pp. 403-407, 2018, doi: 10.1016/j.matpr.2017.11.098.

[10] D. Inserra, G. Wen, "Compact Crossed Dipole Antenna with Meandered Series Power Divider for UHF RFID Tag and Handheld Reade Devices," IEEE Transactions on Antennas and Propagation, vol. 67, no. 6, pp. 4195-4199, 2019, doi: 10.1109/TAP.2019.2905926.

[11] W. Ahmed, Q. Feng, Zh. Xiong, and MK.. Khan, "A Compact Universal Antenna Design for UHF RFID Handheld Reader," Progress in Electromagnetics Research C, vol. 91, pp. 173-183, 2019, doi: 10.2528/PIERC19012505.

[12] W. Ahmed and F. Quanyuan, "A Novel Compact CP Antenna with Wide Axial Ratio Bandwidth for Worldwide UHF RFID Handheld Reader," International Journal of Antennas and Propagation 2019, doi: $10.1155 / 2019 / 2497450$.

[13] A. Ennajih, J. Zbitou, M. Latrach, A. Errkik, L. El Abdellaoui, A. Tajmouati, "A Novel Design of a Miniature Metamaterial Antenna for RFID Reader Applications," TELKOMNIKA (Telecommunication, Computing, Electronics and Control), vol. 16, no. 1, pp. 94-101, 2018, doi: 10.11591/ijece.v7i6.pp3507-3514.

[14] Y. Jung and B. Lee, "Dual-Band Circularly Polarized Microstrip RFID Reader Antenna Using Metamaterial Branch-Line Coupler," IEEE Transactions on Antennas and Propagation, vol. 60, no. 2, pp. 786-791, 2012, doi: 10.1109/TAP.2011.2167943.

[15] M. Ihamji, El. Abdelmounim, H. Bennis, M. Hefnawi, M. Latrach, "Design of Compact Tri-band Fractal Antenna for RFID Readers," International Journal of Electrical and Computer Engineering (IJECE), vol. 7, no. 4, pp. 2036-2044, 2017, doi: 10.11591/ijece.v7i4.pp2036-2044.

[16] Q. Liu, J. Shen, J. Yin, Hongli Liu, and Y. Liu, "Compact 0.92/2.45-GHz Dual-Band Directional Circularly Polarized Microstrip Antenna for Handheld RFID Reader Applications," IEEE Transactions On Antennas and Propagation, vol. 63, no. 9, pp. 3849-3856, 2015, doi: 10.1109/TAP.2015.2452954.

[17] A. K. Verma, D. Dubey, Y. Kumar and A. K. D. Dwivedi, "Defective Ground Structure For Circularly Polarized Microstrip Antenna with an Irregular Slot for 2.45 GHz RFID Reader," in proc. 2017 3rd International Conference on Advances in Computing, Communication \& Automation, 2017, pp. 1-4, doi: 10.1109/ICACCAF.2017.8344680.

[18] A. Hamraoui, E. Abdelmounim, J. Zbitou, H. Bennis, M. Latrach, "Compact Dual-Band Microstrip Slot Antenna for UHF and Microwave RFID Applications," 11th International Conference on Intelligent Systems: Theories and Applications (SITA), 2016, doi: 10.1109/SITA.2016.7772280.

[19] A. Hamraoui, El. Abdelmounim, J. Zbitou, L. Elabdellaoui, H. Bennis, M. Latrach, "A New Compact CPW-Fed Dual-Band Uniplanar Antenna for RFID Applications," TELKOMNIKA (Telecommunication, Computing, Electronics and Control), vol. 16, no. 1, pp. 102-109, 2018, doi: 10.12928/telkomnika.v16i1.7560.

[20] Younes El Hachimi, Yassine Gmih, El Mostafa Makroum, Abdelmajid Farchi, "A Miniaturized Patch Antenna Designed and Manufactured Using Slot's Technique for RFID UHF Mobile Applications," International Journal of Electrical and Computer Engineering (IJECE), vol. 8, no. 6, pp. 5134-5143, 2018, doi: 10.11591/ijece.v8i6.pp5134-5143.

[21] Z. Xing, K. Wei, L. Wang, and J. Li, "Dual-Band RFID Antenna for $0.92 \mathrm{GHz}$ Near-Field and $2.45 \mathrm{GHz}$ Far-Field Applications," International Journal of Antennas and Propagation, 2017, doi: 10.1155/2017/6803019. 
[22] G. Xiao et al., "Printed UHF RFID Reader Antennas for Potential Retail Applications," IEEE Journal of Radio Frequency Identification, vol. 2, no. 1, pp. 31-37, 2018, doi: 10.1109/JRFID.2018.2823640.

[23] H. Tizyi, F. Riouch, A. Najid, A. Tribak, Angel Mediavilla, "Design of a Compact Dual-band Microstrip RFID Reader Antenna," International Journal of Microwave and Optical Technology, vol. 11, no. 2, 2016.

[24] R. Caso, A. Michel, M. Rodriguez-Pino, and P. Nepa, "Dual-Band UHF-RFID/WLAN Circularly Polarized Antenna for Portable RFID Readers," IEEE Transactions on Antennas and Propagation, vol. 62, no. 5, pp. 2822-2826, 2014, doi: 10.1109/TAP.2014.2303971.

[25] A. Azarbar, M. Mashhadi, J. Ghalibafan, "A Novel Circularly Polarized Dual-band Slot Antenna for RFID Applications," IEEE GCC Conference and Exhibition $(G C C)$, February 19-22, 2011, Dubai, United Arab Emirates, doi: 10.1109/IEEEGCC.2011.5752511.

[26] M. S. Kim et al., "Adaptive TX leakage canceler for the UHF RFID reader front end using a direct leaky coupling method," IEEE Trans. Ind. Electron., vol. 61, no. 4, pp. 2081-2087, 2014, doi: 10.1109/TIE.2013.2267932.

[27] J. K. Pakkathillam, M. Kanagasabai and M. G. N. Alsath, "Compact Multiservice UHF RFID Reader Antenna for Near-Field and Far-Field Operations," IEEE Antennas and Wireless Propagation Letters, vol. 16, pp. 149-152, 2017, doi: 10.1109/LAWP.2016.2561960.

[28] E. Farias Fernandes, et al., "2.4-5.8 GHz dual-band patch antenna with FSS reflector for radiation parameters enhancement," Int. J. Electron. Commun. (AEÜ) vol. 108, pp. 235-241, 2019, doi: 10.1016/j.aeue.2019.06.021.

[29] D. Ding, J. Xia, L. Yang and X. Ding, "Multiobjective Optimization Design for Electrically Large Coverage: Fragment-Type Near-FieldVFarField UHF RFID Reader Antenna Design," IEEE Antennas and Propagation Magazine, vol. 60, no. 1, pp. 27-37, 2018, doi: 10.1109/MAP.2017.2774140.

[30] R. A. Oliver, "Broken-loop RFID reader antenna for near field and far field UHF RFID tags," U.S. Design Patent D570, $337 \mathrm{~S}, 2008$.

[31] Ch. Qi, RW. Corless, "Low-power and Compact Frequency Hopping RFID Reader at 5.8 GHz for Sensing Applications in Space," IEEE Journal of Radio Frequency Identification, 2019, doi: 10.1109/JRFID.2019.2926698.

[32] A. Batta, Ruchi, "Multiband Microstrip Patch Antenna for RFID Applications," IJARCCE (International Journal of Advanced Research in Computer and Communication Engineering), vol. 5, no. 8, 2016.

[33] A. L Borja, A. Belenguer, J. Cascon, J. R. Kelly, "A Reconfigurable Passive UHF Reader Loop Antenna for NearField and Far-Field RFID Applications," Antennas and Wireless Propagation Letters, IEEE, vol. 11, pp. 580-583, 2012, doi: 10.1109/LAWP.2012.2200870.

\section{BIOGRAPHIES OF AUTHORS}

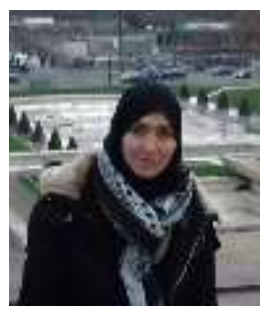

Belgacem Wahiba was born in Tlemcen (Algeria) in 1991, She received a master degree in Telecommunication fild at Tlemcen University in 2014 and Ph.D studiant at Tlemcen University, Algeria 2020. She has been moving into new research areas analysis and design smart antenna. In addition to topics in satellite antenna technology, she is pursuing research in novel platforms such as wearable RFID technology.

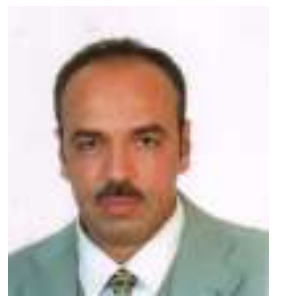

Miloud Bousahla was born in Sidi BelAbbès, Algeria, in 1969. He received the diploma of state engineer in Electronics (1993) from the Sidi BelAbbès University, Magister degree in Electronics (1999) and doctorate degree from Abou Bekr Belka1d University Tlemcen (2012). He is currently a Junior Lecturer in the Abou BekrBelka1d University. Also he is a Junior Researcher within the Telecommunications Laboratory. He works on design, analysis and synthesis of antenna and conformal antenna and their applications in communication and radar systems.

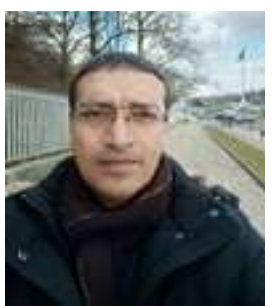

Sidi Mohammed Meriah was born in Tlemcen (Algeria) in 1970. He received the diploma of state engineer in Electronics (1992) from National Polytechnic College, Magister degree in Electronics (1997) and doctorate degree from Tlemcen University (2005). He is a Senior Lecturer in Tlemcen University and he is the Director of the Telecommunications Laboratory LTT. His current research interest includes UWB Antennas, chipless RFID Tag, Reflectarray, heuristic search algorithm, analysis and design smart antenna and array antennas pattern synthesis, RADAR and microwave imaging systems. 